\title{
Investigation on the feasibility of resource utilizing drinking water treatment sludge as a pozzolan to prepare cement-based materials
}

\author{
Qiong Jia ${ }^{1, a}$, Jinsuo $\mathrm{Lu}^{2, b^{*}}$, Jing Yang ${ }^{2, \mathrm{c}}$ \\ ${ }^{1}$ XAUAT UniSA An De College, Xi'an University of Architecture and Technology, Xi'an, Shaanxi, China \\ ${ }^{2}$ School of Environmental and Municipal Engineering, Xi' an University of Architecture and Technology, Xi' an, Shaanxi, China
}

\begin{abstract}
The characteristics of four kinds of sludge obtained from different drinking water treatment plants in Australia and China were contrastively analyzed in this study using x-ray fluorescence, scanning electron microscopy, and x-ray diffraction. The conducted SAI test determined the pozzolanic reactivity of drinking water sludge ash (DWSA), which was derived from the grinding and calcination of drinking water treatment sludge (DWTS). The results indicated that the $\mathrm{Al}_{2} \mathrm{O}_{3}$ and $\mathrm{SiO}_{2}$ were the main components of DWTS, and the main crystalline minerals in DWTS were quartz, kaolinite, and aluminum sulfate hydroxide hydrate, which can be transformed into the reactive amorphous state after calcination at $800{ }^{\circ} \mathrm{C}$. Also, the SAI index of DWSA-derived mortar samples met the requirement, indicating a satisfying pozzolanic reactivity. Therefore, the DWTA was possible to be recycled as a pozzolan in cement-based materials.
\end{abstract}

\section{Introduction}

Drinking water treatment sludge (DWTS) is the aluminum-based waste derived from the drinking water purification processes ${ }^{[1]}$. To meet the required water quality standards, the water treatment plants (WTPs) remove various harmful impurities in raw water through coagulation, precipitation, filtration, and disinfection. Coagulants such as aluminum salt are usually used to destroy the stability between colloids and promote the formation of particle agglomerates ${ }^{[2]}$. In the coagulation process, the coagulant is combined with suspended solids, colloids, organic matter, gravel, and microorganisms in the raw water and forming DWTS after separated from the raw water by precipitation and filtration.

In recent years, domestic and industrial water demand has increased dramatically due to the rapid growth of the global population and economic development, which means large quantities of DWTS have been produced by WTPs ${ }^{[3]}$. It is estimated that the annual production of DWTS by a typical WTP may reach about 100,000 tons and the daily production of DWTS exceed 10,000 tons on a global scale ${ }^{[4]}$. Therefore, the disposal of enormous DWTS has been a major environmental challenge for the water treatment industry. At present, the most widely used treatment methods for sludge in various countries are sanitary landfills after chemical or mechanical dehydration. However, most of the sludge has not been treated innocuously. Thus, disposing of DWTS by sanitary landfill not only wastes land but also may cause environmental issues related to secondary pollution ${ }^{[5]}$. For instance, the rich aluminum in DWTS may be leaching into surrounding water resources and eventually be ingested into the human body by continuous bioaccumulation, which is a risk factor for Alzheimer's disease ${ }^{[6]}$. Therefore, it is essential to dispose of DWTS in an economical and environmentally friendly manner.

Many studies about the resource utilization of sludge have been conducted, such as recovering the coagulants from DWTS for sewage treatment, using DWTS for soil improvement, ceramsite production, and brick making [7${ }^{10]}$. However, due to the complicated procedures and high economic costs, these utilization manners have great limitations in practical applications. To provide a scientific insight into the feasibility of utilizing DWTS in cementbased materials, this study aims to: (i) contrastive analyze the properties of DWTS from four different WTPs, (ii) analyze the possibility of activating sludge by calcination according to its mineralogical composition, (iii) investigate the pozzolanic reactivity of obtained drinking water sludge ash (DWSA).

\section{Materials and Methods}

\subsection{Microstructural characterizations}

The characteristics of DWTS are closely related to the raw water and treatment process of WTPs. To understand the properties of the DWTS, the DWTS taken from four different WTPs were contrastively analyzed. One of the DWTS was taken from the Happy Valley WTP in South Australia, and the rest was taken from three different WTPs in Xi'an, China.

aemail: jiaqiong@xauat.edu.cn, cemail: jingyang2020@xauat.edu.cn,

*Corresponding author: bemail: lujinsuo@xauat.edu.cn 
The chemical composition of four kinds of DWTS was identified using S4 PIONEER spectrometers. The morphology of DWTS was characterized by scanning electron microscopy. Moreover, the D8 ADVANCE X-ray diffractometer was used to obtain the mineralogical composition of DWTS with the scanning angle ranged from 5 to $80^{\circ}(2 \theta)$.

\subsection{Materials preparation}

To investigate the pozzolanic reactivity of DWTS after

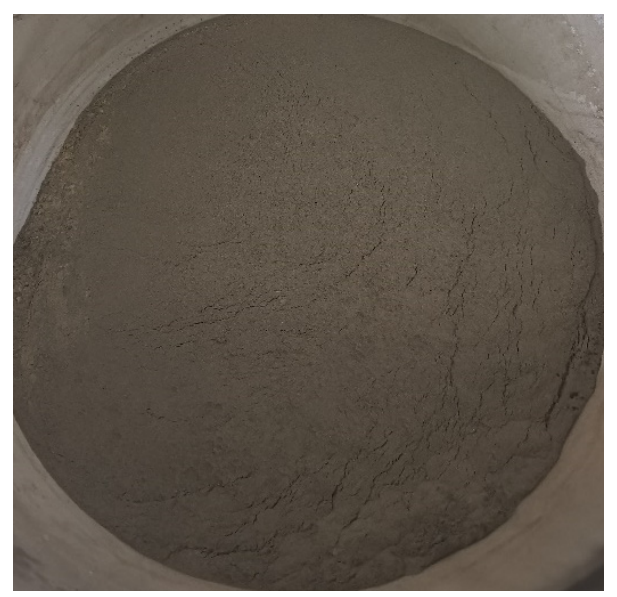

(a) DWTS-Before calcined calcination, the DWTS from South Australia was first dried at $105{ }^{\circ} \mathrm{C}$ for 24 hours. Then, the dried sludge was ground through a ball mill until all the powder passed through a $75 \mu \mathrm{m}$ sieve. The calcination of sludge was conducted in a muffle furnace for $2 \mathrm{~h}$ to obtained DWSA, with the peak temperatures of the furnace were $800{ }^{\circ} \mathrm{C}$. The appearance of sludge before and after calcination is shown in Fig. 1. After drying, grinding, and sieving, the DWTS is light gray powder, while changed to yellow powder after calcination.

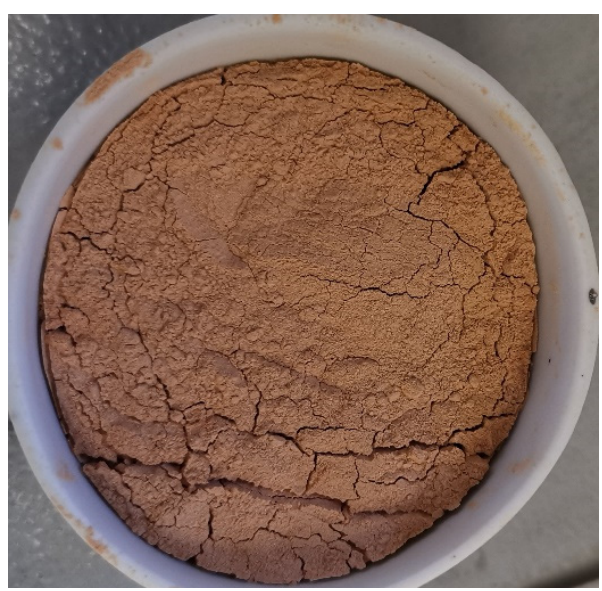

(b) DWSA-After calcined at $800{ }^{\circ} \mathrm{C}$

Fig 1 Appearance of DWTS before and after calcination

\subsection{Pozzolanic activity}

The pozzolanic activity of DWSA was assessed using the strength activity index (SAI) test which conforming to the ASTM C311 (2018). The studied mortars were prepared with $20 \%$ of cement replaced with DWSA, while the reference ones were prepared without DWSA. The SAI was calculated with Eq. (1), where $A$ is the average compressive strength of the studied mortar, and B is the average compressive strength of the reference ones. According to ASTM C618, the SAI at 7 or 28 days greater than 0.75 indicates that the DWSA was pozzolan material.

$$
S A I=\frac{A}{B} \times 100 \%
$$

\section{Results \& Discussion}

\subsection{Chemical components}

The chemical components of four kinds of DWTS are shown in Table 1. The major components of DWTS were $\mathrm{Al}_{2} \mathrm{O}_{3}, \mathrm{SiO}_{2}$, and $\mathrm{Fe}_{2} \mathrm{O}_{3}$, with little difference of DWTS from different WTP. The $\mathrm{Al}_{2} \mathrm{O}_{3}$ content of samples fluctuated between $26 \%-29 \%$, which was impacted by the type and quantity of coagulant used in the water purification process. The silicon in DWTS, with content of $27 \%-30 \%$, mainly came from solid matter in raw water. In addition, there were relatively large differences in calcium content between different DWTS. This might be related to the amount of $\mathrm{Ca}(\mathrm{OH})_{2}$ used by WTPs aimed to adjust the $\mathrm{pH}$ of drinking water. Moreover, there were also some traces of heavy metals such as $\mathrm{Pb}$ and $\mathrm{V}$ in DWTS, which derived from industrial wastewater or impurities in additives added during water treatment.

In general, the DWTS contains a large amount of $\mathrm{Al}_{2} \mathrm{O}_{3}, \mathrm{SiO}_{2}, \mathrm{Fe}_{2} \mathrm{O}_{3}$, and $\mathrm{CaO}$, which components can be used by the hydration process after activated ${ }^{[11]}$. Although there were some heavy metals, the overall content was low. Therefore, from the perspective of chemical composition, the resource utilization of DWTS in cement-based materials is research valuable.

Table 1 Chemical components of four kinds of drinking water treatment sludge.

\begin{tabular}{lllll}
\hline \multicolumn{6}{l}{ Chemical composition } \\
\hline \multirow{2}{*}{ Oxide } & \multicolumn{4}{l}{ Percentage by mass (\%) } \\
\cline { 2 - 5 } & DWTS-1 & DWTS-2 & DWTS-3 & DWTS-4 \\
\hline $\mathrm{SiO}_{2}$ & 26.59 & 28.16 & 28.83 & 26.94 \\
$\mathrm{Al}_{2} \mathrm{O}_{3}$ & 29.35 & 27.76 & 28.60 & 29.54 \\
$\mathrm{Fe}_{2} \mathrm{O}_{3}$ & 4.931 & 6.975 & 5.787 & 4.306 \\
$\mathrm{CaO}$ & 1.73 & 4.014 & 1.39 & 3.975 \\
$\mathrm{CuO}$ & 0.016 & - & 0.018 & - \\
$\mathrm{K}_{2} \mathrm{O}$ & 1.08 & 1.44 & 1.62 & 0.87 \\
$\mathrm{MgO}$ & 0.635 & 1.02 & 0.989 & 0.982 \\
$\mathrm{Na}_{2} \mathrm{O}$ & 0.44 & 0.369 & 0.584 & 0.168 \\
$\mathrm{SO}_{3}$ & 1.15 & 1.18 & 0.773 & 1.65 \\
$\mathrm{P}_{2} \mathrm{O}_{5}$ & 0.254 & 0.558 & 0.290 & 0.355 \\
$\mathrm{~V}_{2} \mathrm{O}_{5}$ & 0.021 & 0.038 & 0.018 & 0.022 \\
\hline
\end{tabular}




\subsection{Morphology characteristics}

Fig. 2 illustrates the SEM images of the DWTS samples. In Fig. 2a, the stratiform structures were observed with irregular particles attached to the surface of DWTS. Some regular reticular substance was visible in Fig. $2 b$ and $d$, which might be the flocculant because they seem like a bridge adsorbing nearby particles and colloidal substances. Also, some crystalline substances were shown in Fig. 2b, which related to the particulate matter in raw water. The

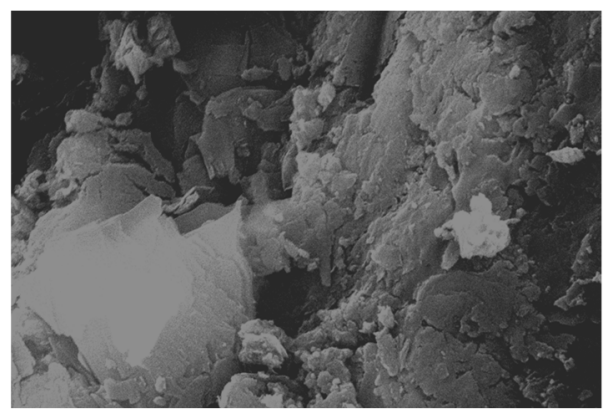

(a) DWTS-1

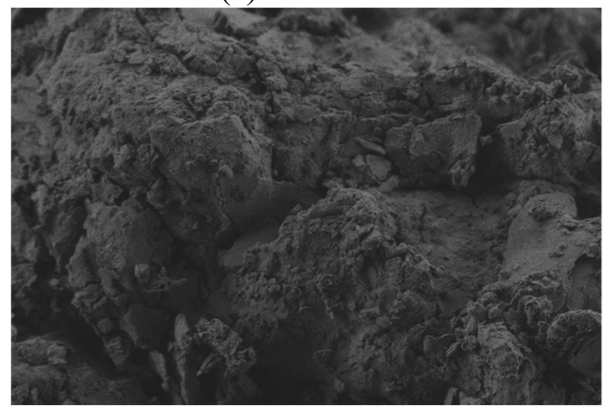

(c) DWTS-3
SEM image of DWTS-3 shows the loose structure of sludge, with obvious cracks on the surface.

These results indicated the inconsistent morphology of different samples, which might be attributed to the complex composition of DWTS, and the morphology shown in the images is just a small portion of the sludge. On the whole, DWTS is composed of various morphologies crystals, colloids, and flocculants, contribute to an irregular shape of sludge particles with a rough and porous surface texture.

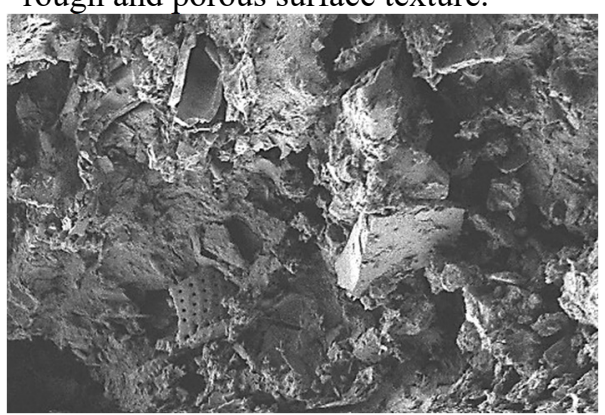

(b) DWTS-2

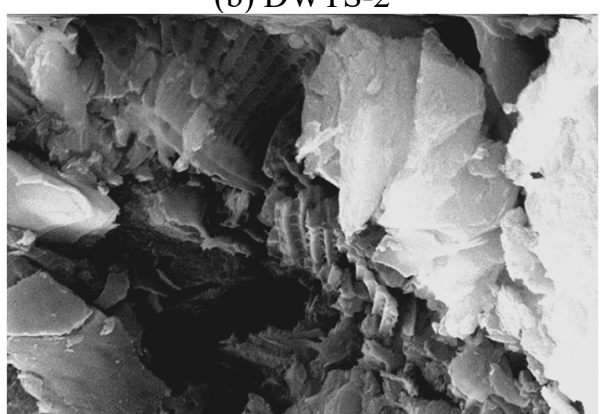

(d) DWTS-4

Fig 2 Microstructures of four kinds of sludge

\subsection{Mineralogical composition}

The mineralogical composition of DWTS is shown in Fig. 3. The results indicated that there was no significant difference in mineral composition between each DWTS. The crystalline content of sludge was dominated by quartz, kaolinite, and aluminum sulfate hydroxide hydrate. Also, the associated minerals, such as albite, lizardite, and microcline were present in small amounts. The diffraction peaks corresponding to calcite were observed in DWTS 1 and 2 due to the presence of this mineral in the particles of raw water.

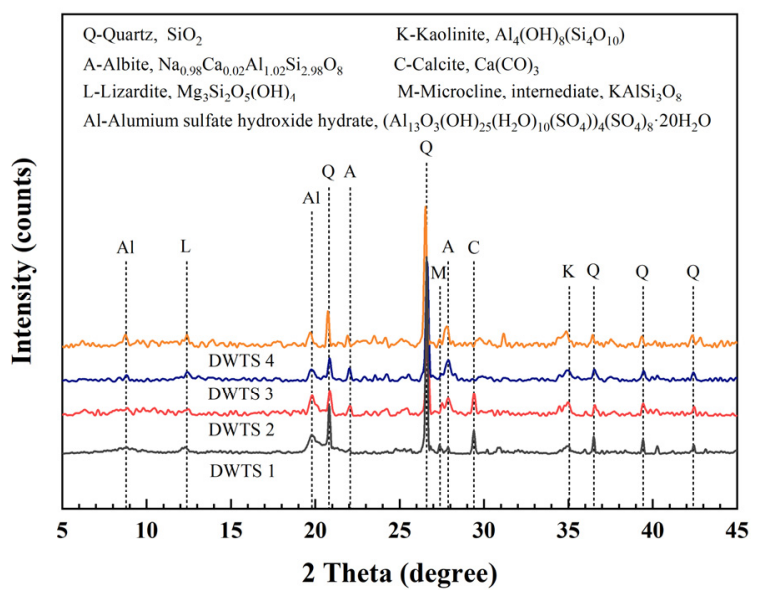

Fig 3 XRD of four kinds of drinking water treatment sludge
The chemical formula of minerals shown in Fig. 3 illustrated that the widely aluminum and silicon in crystalline form existed in DWTS. Referred to the previous investigation by Fernande $z^{[11]}$ about the pozzolanic activity of clay minerals, the minerals especially kaolinite could occur dehydrogenation reaction above $600{ }^{\circ} \mathrm{C}$ and transformed to an amorphous active material. The exposed active silicon and aluminum atoms by calcination make the material pozzolanic active, thus have the potential to participate in the hydration reaction. Therefore, it was worth noting that the diffraction peaks of kaolinite were evidenced in each DWTS, without affected by the water quality and treatment process of WTPs. These results confirmed the possibility of DWTS as supplementary cementitious material from the perspective of mineral composition analysis.

\subsection{Pozzolanic activity}

The three replicates average results of the SAI test are shown in Table 2. The compressive strength of reference mortar prepared without sludge was 31.96 and $37.11 \mathrm{MPa}$ at curing age of $7 \mathrm{~d}$ and $28 \mathrm{~d}$, respectively. The mortar samples containing $800{ }^{\circ} \mathrm{C}$ DWSA showed the satisfied SAI value at all curing ages, with the SAI at 7 and 28 days is $87 \%$ and $114 \%$. These results conform to the standard of ASTM C618, which states the strength of studied samples should exceed $75 \%$ of the control group at 7 or 28 
days. In addition, the significantly increased strength at a later stage indicating the pozzolanic reaction occurred during the hydration process. Thus, these results demonstrate that calcination at $800{ }^{\circ} \mathrm{C}$ can activate the DWSA as a pozzolan material.

Table 2 Strength activity index of DWSA at curing ages of 7 and 28 days.

\begin{tabular}{lccc}
\hline & $\begin{array}{l}\text { Compressive strength of reference } \\
\text { mortar (100\% cement, MPa) }\end{array}$ & $\begin{array}{l}\text { Compressive strength of studied mortar } \\
\mathbf{( 8 0 \%} \text { cement and 20\% DWSA, MPa) }\end{array}$ & SAI \\
\hline 7-day & 31.96 & 27.81 & $87 \%$ \\
28-day & 37.11 & 42.16 & $114 \%$ \\
\hline
\end{tabular}

\section{Conclusions}

This study investigated the feasibility of resource utilizing DWTS in preparation cement-based materials by contrastively analyzed the properties of DWTS taken from different WTPs and the pozzolanic activity of DWSA. From the experimental results, some conclusions can be obtained:

- The chemical composition of DWTS shows a slight influence by the difference of raw water and treatment processes. The main chemical composition of DWTS is $\mathrm{Al}_{2} \mathrm{O}_{3}, \mathrm{SiO}_{2}, \mathrm{Fe}_{2} \mathrm{O}_{3}$, and $\mathrm{CaO}$.

- DWTS particles exhibit an irregular morphology with a rough and porous surface texture. The mineral analysis found that sludge is composed of kaolinite, aluminum sulfate hydroxide hydrate, and some amorphous substances. The aluminum and silicon in the DWTS are widely existed in the crystals and become active amorphous state after calcined by dehydrogenation reaction.

- The DWSA shows a satisfying pozzolanic reactivity based on the results of SAI test.

Therefore, these results illustrate the potential of DWSA as a pozzolan and it is possible to utilize it as supplementary cementitious materials in cement-based material.

\section{References}

1. Frias M, Vigil De La Villa R, De Soto I, et al. (2014) Influence of activated drinking-water treatment waste on binary cement-based composite behavior: Characterization and properties. Composites Part B, 60(C): 14-20.

2. Owaid H M, Hamid R, Taha M R. (2019) Durability properties of multiple-blended binder concretes incorporating thermally activated alum sludge ash. Construction and Building Materials, 200: 591-603.

3. Ahmad T, Ahmad K, Alam M. (2017) Sludge quantification at water treatment plant and its management scenario. Environmental Monitoring and Assessment, 189(9): 453.

4. Ahmad T, Ahmad K, Alam M. (2016) Sustainable management of water treatment sludge through 3 ' $R$ ' concept. Journal of Cleaner Production, 124: 1-13.

5. Zdeb T, Tracz T, Adamczyk M. (2019) Characterisation of basic properties of mineral binders with calcined water treatment sludge. IOP Conference Series: Materials Science and Engineering, 471: 32-34.

6. Exley C. (2017) Aluminum should now be considered a primary etiological factor in Alzheimer's Disease. Journal of Alzheimer's disease reports, 1(1): 23.

7. Parsons S A, DANIELS S J. (1999) The use of recovered coagulants in wastewater teatment. Environment Technology, (20): 42-49.

8. Espejel A F, Schouwenaars R, Duran M A, et al. (2013) Use of drinking water sludge in the production process of zeolites. Research on Chemical Intermediates, 2919-2928.

9. Anyakora N V. (2012) Characterisation and performance evaluation of water works sludge as bricks material. International Journal of Engineering and Applied Sciences, 3(3): 69-79.

10. Huang C, Pan J R, Sun K D, Liaw C T. (2001) Reuse of water treatment plant sludge and dam sediment in brick making. Water Science \& Technology, 44(10), 273-277.

11. Fernandez R, Martirena F, Scrivener K L. (2011) The origin of the pozzolanic activity of calcined clay minerals: A comparison between kaolinite, illite and montmorillonite. Cement and Concrete Research, 41(1): 113-122. 